\title{
Polyarteritis nodosa in a patient on hemodialysis; a case report
}

\author{
Amirhesam Alirezaei $^{\circledR}$, Behrang Kazeminezhad ${ }^{2}$, Babak Sabet ${ }^{3}$, Arman Ahmadzadeh ${ }^{4}$, Rouzbeh Danialy ${ }^{5 *}$ \\ ${ }^{1}$ Urology and Nephrology Research Center, Shahid Modarres Hospital, Shahid Beheshti University of Medical Sciences, \\ Tehran, Iran \\ ${ }^{2}$ Department of Pathology, Shahid Modarres Hospital, Shahid Beheshti University of Medical Sciences, Tehran, Iran \\ ${ }^{3}$ Department of Surgery, School of Medicine, Shahid Beheshti University of Medical Sciences, Tehran, Iran \\ ${ }^{4}$ Department of Rheumatology, Loghman Hakim Hospital, Shahid Beheshti University of Medical Sciences, Tehran, Iran \\ ${ }^{5}$ Department of Internal Medicine, Shahid Beheshti University of Medical Sciences, Tehran, Iran
}

\section{*Correspondence to}

Rouzbeh Danialy, Email: danialyrouzbeh2@gmail.com, danialyrouzbeh@sbmu.ac.ir

Received 3 May 2019 Accepted 17 June 2019 Published online 14 July 2019

Keywords: Polyarteritis nodosa, End-stage renal disease, Hemodialysis, Necrotizing vasculitis

Citation: Alirezaei A, Kazeminezhad B, Sabet B, Ahmadzadeh A, Danialy R. Polyarteritis nodosa in a patient on hemodialysis; a case report. Immunopathol Persa. 2019:5(2):e18. DOI:10.15171/ ipp. 2019.18

\begin{abstract}
We represent a 40-year-old woman with end-stage renal disease (ESRD) of unknown etiology referred to the emergency department with episodes of chills and fever during hemodialysis. Further assessments revealed vasculitic skin rashes, as well as abdominal tenderness and later on, bloody diarrhea. Abdominal pain worsened during the course of admission, and as a result, the patient underwent cholecystectomy and appendectomy. Necrotizing vasculitis was diagnosed based on biopsy specimens taken from gall bladder and skin rashes. The diagnosis of poly arteritis nodosa (PAN) was established based on pathologic report and rheumatologic tests. Methylprednisolone pulses were administrated for 3 days followed by oral prednisolone and cyclophosphamide. After treatment, the signs and symptoms subsided. The present case report highlights the importance of timely diagnosis of PAN to prevent potentially irreversible consequences.
\end{abstract}

\section{Introduction}

Poly arteritis nodosa (PAN) is a multi-system necrotizing vasculitis of small and medium sized muscular arteries with characteristic involvement of the renal and visceral arteries $(1,2)$. Renal disease symptoms can vary from chronic hypertension due to narrowing of the renal arteries and thus activation of the renin-angiotensin system (3) to ESRD. Although pulmonary vasculature is not inflicted in this disease, bronchial arteries may be involved. Granulomas, significant eosinophilia and allergic diathesis are generally absent, and unlike other vasculitides, PAN is not associated with antineutrophil cytoplasmic antibodies (ANCA) (4).

\section{Case Presentation}

A 40-year-old woman was referred to the emergency department with history of fever and chills during hemodialysis. She was a known case of end-stage renal disease (ESRD) and has been under hemodialysis by internal jugular permcath as the dialysis route access thrice weekly for the past 8 months. The episodes of fever and chills

\section{Key point}

Vascular lesions in poly arteritis nodosa (PAN) are characterized by transmural necrotizing inflammation of small and medium-sized muscular arteries. Necrosis of the arterial wall results in a homogenous, eosinophilic appearance referred as fibrinoid necrosis. Renal failure is one of the most common manifestations of PAN and is seen in almost $60 \%$ of the cases.

during dialysis had first started about one month prior to the current admission. The patient also mentioned periodic abdominal pain which was a generalized pain with no radiation or specific position and was not related to feeding. One month before current admission upper endoscopy showed no pathology. The severity of pain was intensified during the course of the disease. Furthermore, the patient gradually showed nausea and vomiting, and diarrhea (loose stool without apparent blood). Since a few days before admission, palpable purpuric lesions on the distal parts of upper and lower extremities were noted. She had recently been admitted to a local hospital and

\footnotetext{
Copyright (C) 2019 The Author(s); Published by Nickan Research Institute. This is an open-access article distributed under the terms of the Creative Commons Attribution License (http://creativecommons.org/licenses/by/4.0), which permits unrestricted use, distribution, and reproduction in any medium, provided the original work is properly cited.
} 
received antibiotic therapy, however no improvement had been achieved. Other than hypertension for the past seven years, she had no remarkable points in her past medical history. Amlodipine and losartan were administrated to control hypertension.

Prior ultrasound study had revealed small size echogenic kidneys (no further study was conducted to clarify accurate diagnosis for the underlying pathology of ESRD).

\section{Physical examination}

The patient was conscious at admission. The vital signs were as blood pressure; 150/94 $\mathrm{mm} \mathrm{Hg}$, pulse rate; 74 beats per minute (bpm), respiratory rate; 16 per minute, and oral temperature was $39^{\circ} \mathrm{C}$. Other findings in physical examination included pale conjunctiva and dry oral mucosa. No signs of infection at the exit site of the indwelling catheter nor tenderness on subcutaneous tunnel were observed. The heart and lung examinations were unremarkable. Positive shifting dullness as well as generalized tenderness without rebound tenderness and guarding were found in abdominal physical examination. Widespread purpuric non-blenching lesions were seen on the distal parts of all four limbs.

\section{Differential diagnosis}

The most common differential diagnoses of fever and chills in ESRD patients were considered. These included catheter infection, sepsis due to meningococcemia, subacute bacterial endocarditis and finally vasculitis. The patient underwent plain abdominal X-ray, chest X-ray and abdominopelvic ultrasound. No significant ultrasound findings were noticed except for moderate amount of ascites. Laboratory findings of the patients are illustrated in Table 1.

\section{Treatment}

The patient was admitted to the nephrology ward for further evaluations. Serial Blood cultures as well as urine culture revealed no microbial growth. Empiric antibiotic therapy was initiated after obtaining serial blood cultures and urine culture samples.

Punch biopsies of skin lesions were obtained, and the samples were sent for microscopic studies. Rheumatologic tests revealed negative P-ANCA $(0.6 \mathrm{u} / \mathrm{mL})$, C-ANCA $(0.2 \mathrm{u} / \mathrm{mL})$, and anti-ds DNA $(0.5 \mathrm{IU} / \mathrm{mL})$, along with borderline ANA (0.8 titer).

Serum IgA level was $257 \mathrm{mg} / \mathrm{dL}$ (reference range;70-400 $\mathrm{mg} / \mathrm{dL}$ ). The results of serum complement proteins were as C3; $95 \mathrm{mg} / \mathrm{dL}$ (reference range; $90-180 \mathrm{mg} / \mathrm{dL}$ ), C4; 21 $\mathrm{mg} / \mathrm{dL}$ (reference range; 10-40 mg/dL), and CH50: $94 \mathrm{u} /$ $\mathrm{mL}$ (reference range; $70-150 \mathrm{u} / \mathrm{mL}$ ).

During the course of admission, rebound tenderness was developed and patient's abdominal pain aggravated. She also mentioned blood in her stool. The patient underwent abdominal-pelvic CT scan with intravenous and oral contrast that revealed moderate ascites and increased intestinal wall thickness in the right lower quadrant. The gall bladder also showed increased thickness and few small stones.

Liver function tests and pancreatic enzymes were AST; $21 \mathrm{U} / \mathrm{L}, \mathrm{ALT} ; 21 \mathrm{U} / \mathrm{L}, \mathrm{ALP} ; 366 \mathrm{U} / \mathrm{L}$, total bilirubin; 0.66 $\mathrm{mg} / \mathrm{dL}$, direct bilirubin; $0.21 \mathrm{mg} / \mathrm{dL}$, and serum amylase and lipase were $41 \mathrm{U} / \mathrm{L}$ and $22 \mathrm{IU} / \mathrm{L}$ respectively.

Urgent surgery counseling was requested in order to assess surgical emergencies such as ischemic colitis. The surgeon suggested explorative laparotomy which revealed massive intra-abdominal fluid and thickening and stones in the gall bladder. Cholecystectomy and appendectomy were done while fluid and tissue samples were sent for pathologic studies.

Pathologic assessments on the gall bladder sample revealed segmental necrotizing vasculitis involving the cystic artery (Figures 1 and 2). The biopsies of skin lesions also showed fibrinoid necrosis of dermal arteries (Figure 3).

The patient was administrated with intravenous methyl prednisolone $(500 \mathrm{mg})$ for three consecutive days to manage vasculitis. After that, oral corticosteroid $(1 \mathrm{mg} / \mathrm{kg}$ prednisolone per day) and cyclophosphamide (endoxan $50 \mathrm{mg}$ daily) were initiated. Following these therapeutic regimens, the signs and symptoms gradually improved (Figure 4). Finally, the patient was discharged with a stable clinical condition.

\section{Discussion}

In the present report, the most probable diagnosis is PAN.

Table 1. Laboratory data of the patient

\begin{tabular}{|c|c|c|c|c|}
\hline $\mathrm{CBC} /$ diff & $\begin{array}{l}\text { WBC: } 5400 / \mu \mathrm{L} \\
\text { P: } 73.1 \% \\
\text { L: } 18.2 \%\end{array}$ & $\begin{array}{l}\mathrm{Hb}: 8.1 \mathrm{~g} / \mathrm{dL} \\
\mathrm{MCV}: 87.7 \mathrm{fl}\end{array}$ & Plt : $171000 / \mu \mathrm{L}$ & \\
\hline \multirow[t]{3}{*}{ Venous blood gas analysis } & $\mathrm{pH}: 7.47$ & PCo2:31.1 & $\mathrm{HCo} 3: 21 \mathrm{meq} / \mathrm{L}$ & \\
\hline & $\begin{array}{l}\text { Urea: } 44 \mathrm{mg} / \mathrm{dL} \\
\text { Creatinine: } 4.83 \mathrm{mg} / \mathrm{dL}\end{array}$ & $\begin{array}{l}\mathrm{Na}: 136 \mathrm{meq} / \mathrm{L} \\
\mathrm{K}: 4.4 \mathrm{meq} / \mathrm{L}\end{array}$ & $\begin{array}{l}\text { Calcium: } 7.7 \mathrm{mg} / \mathrm{dL} \\
\text { Phosphorus: } 5.6 \mathrm{mg} / \mathrm{dL}\end{array}$ & Albumin: $2.9 \mathrm{~g} / \mathrm{dL}$ \\
\hline & $\begin{array}{l}\text { Iron: } 24 \mathrm{mcg} / \mathrm{L} \\
\text { TIBC: } 451 \mathrm{mcg} / \mathrm{ml} \\
\text { Ferritin: } 926 \mathrm{ng} / \mathrm{ml}\end{array}$ & $\begin{array}{l}\text { Intact PTH:88 pg/ml } \\
\text { Vitamin D3:16 ng/ml }\end{array}$ & & \\
\hline Ascites analysis & Serum-ascites albumin gradient (SAAG): 1 & $\begin{array}{l}\text { Fluid albumin: } 1.9 \mathrm{~g} / \mathrm{dL} \\
\text { Serum Alb:2.9 g/dL }\end{array}$ & $\begin{array}{l}\text { Fluid protein: } 3.1 \mathrm{~g} / \mathrm{dL} \\
\text { Total protein: } 5.1 \mathrm{~g} / \mathrm{dL}\end{array}$ & $\begin{array}{l}\text { WBC: } 2600 / \mu \mathrm{L} \\
\text { Neutrophil: } 80 \%\end{array}$ \\
\hline
\end{tabular}




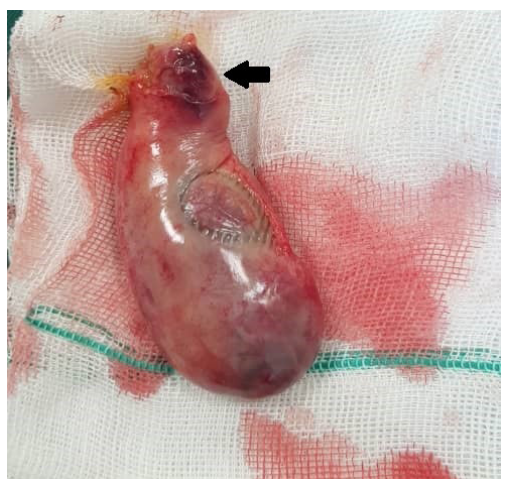

Figure 1. Macroscopic evaluation of gall bladder. Necrotizing areas can be seen specially on the cervical zone.
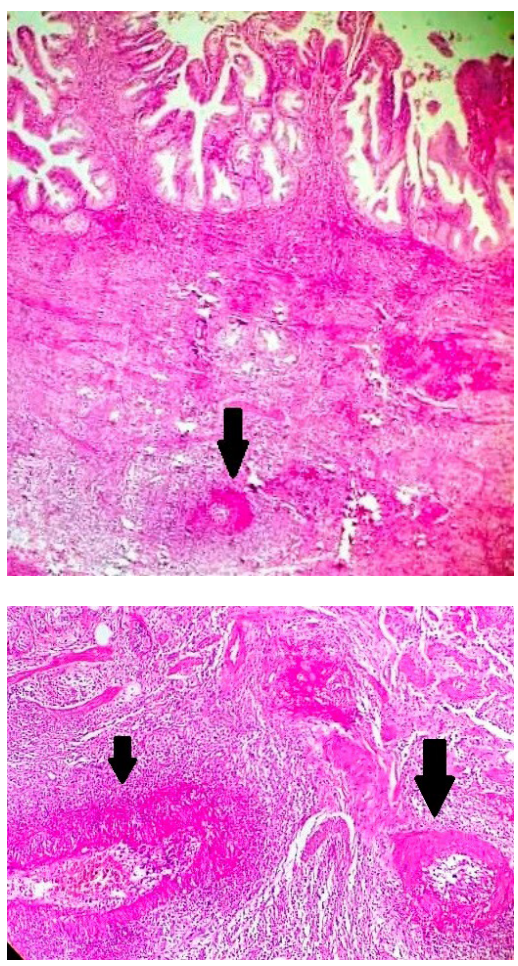

Figure 2. Gall bladder biopsy examination showing necrotizing vasculitis (black arrows).

Abdominopelvic CT scan did not reveal any aneurysm although CT angiography is the modality of choice. However, there is at least three important issues regarding this diagnosis. First; severe fibrinoid necrosis is hallmark of PAN that was seen in our patient. Second; cystic artery involvement which is a medium sized artery and third one, was the presence of necrotizing cholecystitis.

This was the first report of PAN in a patient with ESRD, on hemodialysis. The patient had history of hypertension for the past seven years and was recently diagnosed with ESRD of unknown etiology. The presence of PAN might be suspected by the clinical and radiologic findings however; the diagnosis should definitely be confirmed by biopsy of
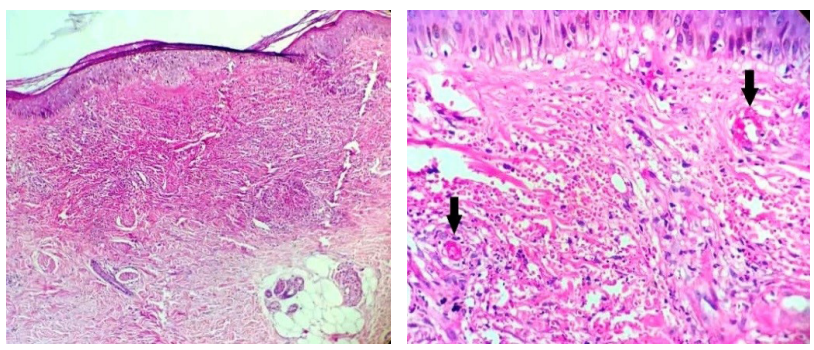

Figure 3. Skin lesions biopsy examination revealed fibrinoid necrosis (black arrows).

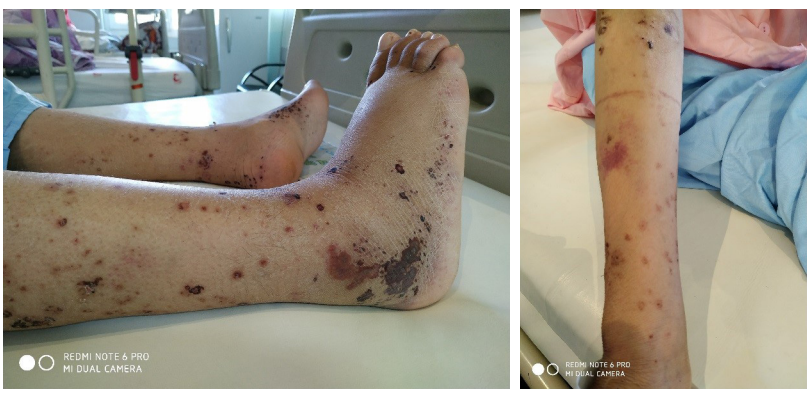

Figure 4. Skin rashes improved after treatment of vasculitis with intravenous and oral corticosteroids.

clinically affected organs (5).

In fact, tissue biopsy examination is the cornerstone of the diagnostic process in PAN. Vascular lesions in PAN are characterized with transmural necrotizing inflammation (2) of small and medium-sized muscular arteries. Characteristically, veins are not involved in PAN. The lesions are segmental and tend to involve bifurcation and branches of the arteries (6). The cellular infiltrates constitute polymorphonuclear leukocytes and mononuclear cells. Necrosis of the arterial wall results in a homogenous, eosinophilic appearance referred as fibrinoid necrosis (6). This feature was apparent in tissue biopsies obtained from our patient.

Clinically, histories of episodic fever and abdominal pain were observed in our patient. Actually, patients with PAN usually represent with vague symptoms such as weakness, malaise, headache, abdominal pain, fever and arthralgias; however, these symptoms can rapidly progress to a fulminant illness. The clinical picture can be complicated with signs and manifestations related to organs involvement. These include skin lesions, hypertension, renal insufficiency, neurologic dysfunction and abdominal pain. Nonetheless, patients might not have all the signs and symptoms at once. Accordingly, we found signs related to skin lesions, as well as renal and gastrointestinal involvements in our patient.

There are currently no diagnostic serologic tests for PAN, and the diagnosis is mainly based on the characteristic findings of vasculitis in biopsy specimens of the involved organs, as well as features in renal angiogram $(2,6)$. 
The prognosis of untreated PAN is extremely poor with a reported 5-year survival rate of $10 \%$ to $20 \%$ (an average rate of $13 \%)(1,7)$. Renal failure, as well as mesenteric, cardiac or cerebral infarctions are the major causes of death (5). With the introduction of effective treatments, the survival rate has currently increased reaching a 5 -year survival rate of approximately $80 \%$ (8). In the present case, a favorable outcome was obtained following treatment with steroids and cyclophosphamide. It has been reported that the combination of prednisolone and cyclophosphamide (and glucocorticoids alone in milder forms of PAN) can result in durable disease remission.

\section{Conclusion}

Renal failure is one of the most common manifestations of PAN and is seen in almost $60 \%$ of the cases. If underdiagnosed, renal failure can lead to death in patients with PAN. In general, any delay in the diagnosis of PAN or underestimation of its renal manifestations can lead to disease progression and clinical deterioration as seen in our patient.

\section{Authors' contribution}

$\mathrm{AHA}, \mathrm{BK}, \mathrm{BS}, \mathrm{AA}$ and RD participated in the conception of the case report, data collection and drafted the manuscript. AHA, BK, BS, AA and RD contributed to drafting, critical reviewing, and finalization of the manuscript. All authors contributed to development of the manuscript and approved the final manuscript

\section{Conflicts of interest}

The author declared no competing interests.
Ethical considerations

Ethical issues including plagiarism, double publication, and redundancy have been completely observed by the author. The patient gave her consent to be published as a case report.

Funding/Support

None

\section{References}

1. Balow JE. Renal vasculitis. Kidney Int .1985;27:954-64.

2. Jennette JC, Thomas DB, Falk RJ. Microscopic polyangiitis (microscopic polyarteritis). Semin Diagn Pathol. 2001;18:3-13.

3. Stockit JR, Topliss DJ, Hewett MJ. high -renin hypertension in necrotizing vasculitis. N Eng J Med. 1979; 300:1218. DOI:10.1056/NEJM197905243002115.

4. Kallenberg CG, Brouwer E, Weening JJ, Tervaert JW. antineutrophil cytoplasmic antibodies: current diagnostic and pathophysiological potential. Kidney Int .1994; 46:1-15.

5. Merkel PA, Matteson EL, Curtiz MR. treatment and prognosis of poly arteritis nodosa. Uptodate. 2017.

6. Ng WF, Chow LT, Lam PW. Localized polyarterities nodosa of breast report of two cases and a review of the literature. Histopathology. 1993; 23:535-9.

7. Frohnert PP, Sheps SG. long term follows up study of periarteritis nodosa. Am J Med. 1967; 43:8-14. doi:10.1016/00029343(67)90144-1.

8. Pagnoux C, Seror R, Henegar C, Mahr A, Cohen P, Le Guern $\mathrm{V}$, et al . clinical features and outcomes in 348 patients with polyarteritis nodosa: a systematic retrospective study of patients diagnosed between 1963 and 2005 and entered into the French vasculitis study group database. Arthritis Rheum. 2010;62:616-26. doi: 10.1002/art.27240. 